\title{
East-West Asymmetry in Coastal Temperatures of Hudson Bay as a Proxy for Sea Ice
}

\author{
Peter G. McGovern ${ }^{1}$ and William A. Gough ${ }^{1,2}$
}

(Received 5 May 2014; accepted in revised form 4 May 2015)

\begin{abstract}
Hudson Bay experiences a complete cryogenic cycle, which has been well documented since 1971. We developed a temperature proxy method to extend the sea ice record back to 1944, using mean temperatures for Churchill and Inukjuak and the difference between these means at two different seasonal periods. This method proved to reproduce the 1971 to 2011 ice-free season length record with an error just over eight days (6\%). This relationship was used to hindcast ice-free season length to 1944. This hindcast was subsequently appended to the existing 1971-2011 record to form a 68-year sea ice record. This extended record shows that the recent statistically significant increase in length of the ice-free season was not the result of a natural oscillation of less than 68 years and is consistent with a net warming due to increasing greenhouse gases.
\end{abstract}

Key words: sea ice; Hudson Bay; hindcast; temperature proxy; climate change

RÉSUMÉ. La baie d'Hudson connaît un cycle cryogénique complet, et celui-ci est bien répertorié depuis 1971. Nous avons élaboré une méthode d'obtention de données indirectes des températures afin d'étendre les données des températures jusqu'à 1944, en nous servant des températures moyennes pour Churchill et Inukjuak et de la différence entre ces moyennes à deux périodes saisonnières différentes. Cette méthode avait pour but de reproduire le registre des durées de saisons sans glace de 1971 à 2011, avec une marge d'erreur d'un peu plus de huit jours (6 \%). Cette méthode a permis de faire la simulation rétrospective de la durée des saisons sans glace jusqu'en 1944. Par la suite, la simulation rétrospective a été appliquée au registre actuel de 1971-2011, ce qui a donné lieu à un registre sur la glace de mer réparti sur 68 années. Ce registre prolongé a permis de démontrer que la récente augmentation statistiquement différente en matière de durée de la saison sans glace ne découlerait pas d'une oscillation naturelle de moins de 68 ans, et qu'elle correspond à un réchauffement net attribuable à l'augmentation des gaz à effet de serre.

Mots clés : glace de mer; baie d'Hudson; simulation rétrospective; données indirectes des températures; changement climatique

Traduit pour la revue Arctic par Nicole Giguère.

\section{INTRODUCTION}

As the second largest bay in the world, occupying $1300000 \mathrm{~km}^{2}$, northern Canada's Hudson Bay exerts a powerful influence over the regional climate (Martini, 1986). Hudson Bay (HB, the Bay, Fig. 1) is also the largest water body in the world to undergo an annual cycle between total sea ice coverage and complete open water. This annual cryogenic cycle adds another layer of complexity to the regional climate, as the interaction between the Bay and the boundary layer atmosphere fluctuates considerably on a seasonal basis. Open water bodies have a significant impact on local and regional climate through exchanges of heat, moisture, and momentum with the air above them. Sea ice acts to limit this exchange of energy and mass between atmosphere and water, thus reducing or eliminating these effects (Niziol, 1987; Gerbush et al., 2008; McPhee, 2008). Differences between water and sea ice in physical properties, most importantly in their ability to reflect shortwave radiation, increase the contrast between the energy budgets of an ice-covered vs. an ice-free water body (McPhee, 2008). On Hudson Bay, the seasonality of sea ice, combined with the prevailing westerly winds, creates an interesting seasonal asymmetry in coastal temperatures. During the ice-free season, winds arriving on the east coast are thermally modified through advection over the open water, leading to generally warmer conditions than on the west coast. This asymmetric temperature signal is most pronounced following annual extremes of sea ice cover.

This study aims to determine whether the coastal temperature difference signal contains sufficient information regarding ice conditions to help extend the sea ice record for Hudson Bay by proxy. Consistent satellite-derived sea ice data do not exist for this area prior to 1971, so any extension or improvement to that record would benefit climatologists by allowing for more confident trend analysis. More specifically, a longer time series would help distinguish anthropogenic change from natural variability.

Thus far, studies on the use of temperature records as a proxy for sea ice in Hudson Bay and the broader Arctic

\footnotetext{
${ }^{1}$ Department of Physical and Environmental Sciences, University of Toronto Scarborough, 1265 Military Trail, Scarborough, Ontario M1C 1A4, Canada

${ }^{2}$ Corresponding author: gough@utsc.utoronto.ca

(C) The Arctic Institute of North America
} 


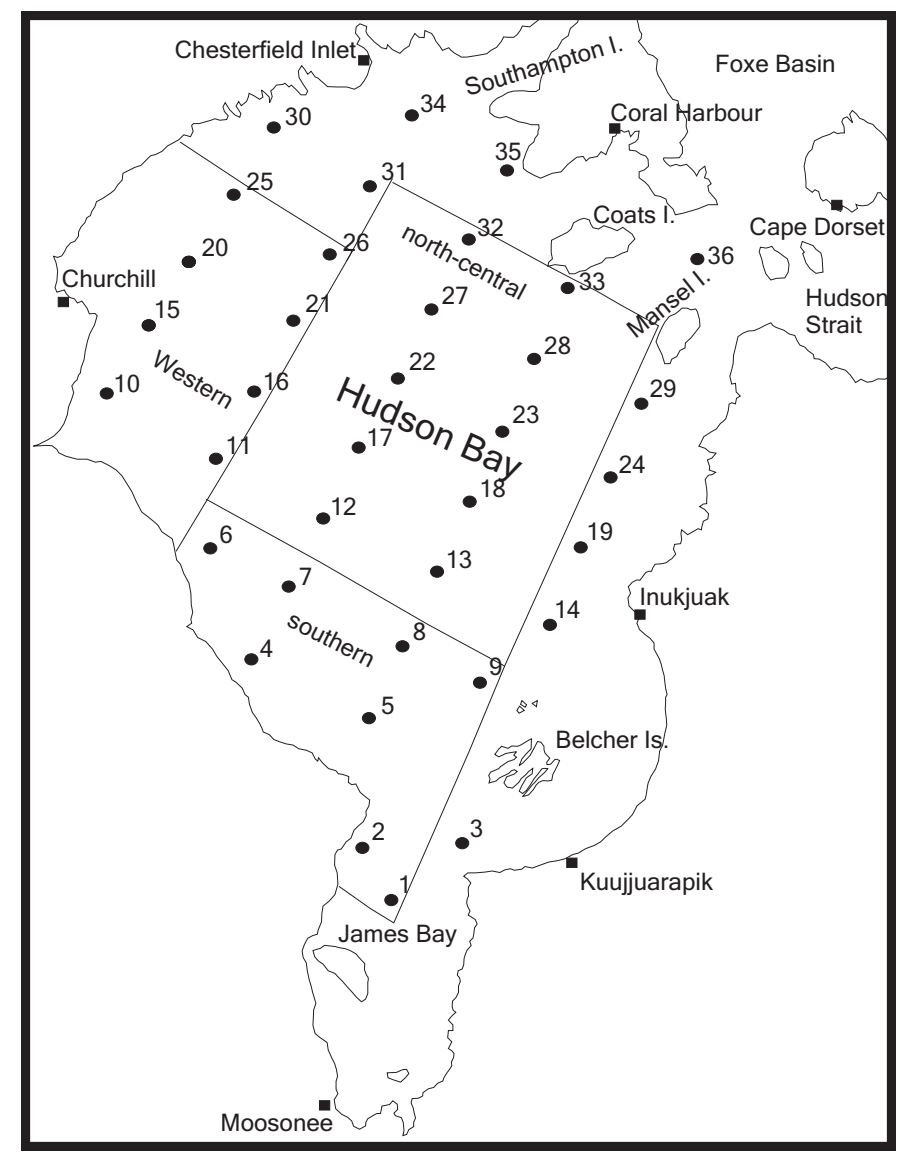

FIG. 1. Site map of Hudson Bay indicating the location of the 36 points for which breakup and freeze-up dates were derived (Gagnon and Gough, 2005). The region spans $51^{\circ}$ to $63^{\circ} \mathrm{N}$ and is centered along $90^{\circ} \mathrm{W}$.

are scant, although the relationship between the two is well documented for Hudson Bay (Hochheim and Barber, 2010, 2014; Galbraith and Larouche, 2011; Hochheim et al., 2011; Joly et al., 2011). More often, broad estimates of sea ice conditions are inferred indirectly from temperatures at coarse temporal scales, which themselves have been derived via other proxies (Isaksson et al., 2005; Macias Fauria et al., 2010; Polyak et al., 2010). The reason may be that temperatures serve only as a coarse stand-in for sea ice and therefore are useful only when there are no superior alternatives. However, a few studies focusing on the HB region have demonstrated some success in predicting ice conditions using temperature along with other variables (Gough and Houser, 2005; Tivy et al., 2007, 2011). Sea ice advance and retreat dates on Hudson Strait can be predicted within a week given ice data for the preceding ice-free or ice-covered season (Gough and Houser, 2005). Including average air temperature during the ice-free season in this method yielded improved ice retreat predictions for certain locations. On Hudson Bay proper, basin-averaged air temperature shows a weak correlation with concurrent ice thickness, but its influence is seen as secondary to that of other factors, such as snow depth (Gough et al., 2004b). A stronger relationship exists at the local level between summer temperatures and ice thickness during the subsequent ice-covered season, suggesting that preconditioning or thermal memory is more determinant than coincident temperatures (Gough et al., 2004b). The reliance of these methods on sea ice and snow depth data precludes their utility for hindcasting, but taken together, they show there is some predictive value in air temperature data alone when focusing on the proper indices and physical relationships to ice.

Given the Bay's lake-like morphology, studies demonstrating some success with temperature-based proxies for lake ice may shed light on the method's feasibility (Etkin, 1991; Saucier and Dionne, 1998; Gough and Allakhverdova, 1999). In a comprehensive analysis of lake ice records for all Canadian lakes, Williams (1971) found that the breakup date (defined in this case as the date at which the lake is $100 \%$ ice-free) was predicted within a standard error of 1.6-4.3 days if the date of the start of breakup was known as well as temperatures for the duration of the melting period. In other cases, the predictor and predictand in the lake ice-temperature coupling might be reversed, so that ice conditions serve as a proxy for air temperature. This approach has shown some success in reconstructing local air temperatures for areas with extensive ice records. For example, the timing of ice breakup on a high-altitude lake in the Swiss Alps was shown to have a shared variance of $64 \%$ with local air temperatures (Livingstone, 1997). In this case, if the ice records predate those of temperature, breakup dates may be used as part of a multi-proxy approach to hindcast local air temperature. However, other factors, such as local weather, lake morphometry, and sheltering, prevent a more direct relationship between the two variables and hence limit the accuracy of such predictions. In a similar study based on lakes in Finland, Palecki and Barry (1986) suggested that freeze-up and breakup dates derived from satellite observations could be used as a proxy for air temperature in mid-to-high latitudes that lacked data coverage. They drew this conclusion from the fact that they could correlate changes in dates of freeze-up and breakup to a certain change in mean monthly temperature leading up to that date. However, the regression coefficients varied across the country and were suitable for hindcasting temperature only for an area a few hundred kilometers in diameter.

The dearth of studies aimed at using temperature as a proxy for sea or lake ice, or vice versa, may indicate the inadequacies of such an approach. Indeed, of the few studies found that do show some predictive value in certain sea ice-temperature correlation models for a specific area, the authors admit that such predictions are improved upon or made redundant by complementary or alternative approaches employing other proxies. The limited spatial scale of the studies that demonstrate some predictive value also points to the limitations of this approach. As scale increases, the temperature/ice signal may be increasingly overridden by the effects of synoptic scale systems. Similar challenges undoubtedly face the proposed proxy for Hudson Bay. However, the unique relationship between coastal temperatures and sea ice is both highly site-specific and 
without precedent. Thus, if the temperature difference signal is stronger than or complementary to the more established absolute temperature relationship, it may contribute valuable information on past ice conditions.

\section{METHODS}

\section{Data}

The Canadian Ice Service has issued sea ice concentration (SIC) data for Hudson Bay in the form of weekly ice charts since 1971. Using the methodology of Etkin (1991), these ice charts have been used to determine breakup and freeze-up dates for 36 uniformly distributed geographical points on the Bay (Gagnon and Gough, 2005).

Breakup and freeze-up dates are usually defined as the earliest day of the year (DOY) when the SIC is below or above 5/10, respectively (Stirling et al., 1999; Gough et al., 2004a; Gagnon and Gough, 2005). Ice-free season (IFS), defined as the number of days between the breakup date and the freeze-up date, is thus easily determined for all 36 points. A single IFS value was obtained for each year by spatially averaging 36 geographical points, since it is assumed that the temperature asymmetry between coasts is being shaped by ice conditions across the entire Bay. Though this spatially averaged value ignores the inherently heterogeneous nature of ice cover on the Bay, it serves a purpose here as a simplified metric to represent ice conditions across the entire Bay that year.

Daily mean air temperature data were obtained from Environment Canada's climate database for two sites on opposite coasts of the Bay: Churchill and Inukjuak. The town of Churchill is located in the northern region of Manitoba, on the west coast of the Bay, at $58^{\circ} 46^{\prime} 09^{\prime \prime} \mathrm{N}, 94^{\circ} 10^{\prime} 09^{\prime \prime} \mathrm{W}$. Inukjuak is a village and Inuit community located in the Nord-du-Québec region, on the east coast of the Bay, at $58^{\circ} 27^{\prime} 00^{\prime \prime} \mathrm{N}, 78^{\circ} 06^{\prime} 00^{\prime \prime} \mathrm{W}$. The fact that the two sites are less than half a degree of latitude from each other means it is reasonable to assume negligible climatic variability owing to latitudinal differences. Since there are no other local climate factors that would account for a significant difference in their temperatures, it is assumed that the bulk of the temperature asymmetry would be attributable to ice cover.

With the selection of a single representative site for each coast of the Bay, the temperature asymmetry was simply defined as the difference in air temperature between the two sites at any given point in time.

$$
\Delta \mathrm{T}=\mathrm{T}_{\text {CHURCH }}-\mathrm{T}_{\text {INUK }}
$$

By this definition, a positive $\Delta \mathrm{T}$ indicates that Churchill was warmer than Inukjuak for that time interval, while a negative $\Delta \mathrm{T}$ indicates that Inukjuak was warmer than Churchill. To characterize the behavior of $\Delta \mathrm{T}$ during an average year, a daily climate normal was constructed by averaging daily $\Delta \mathrm{T}$ values over all available years for all 366 days. This

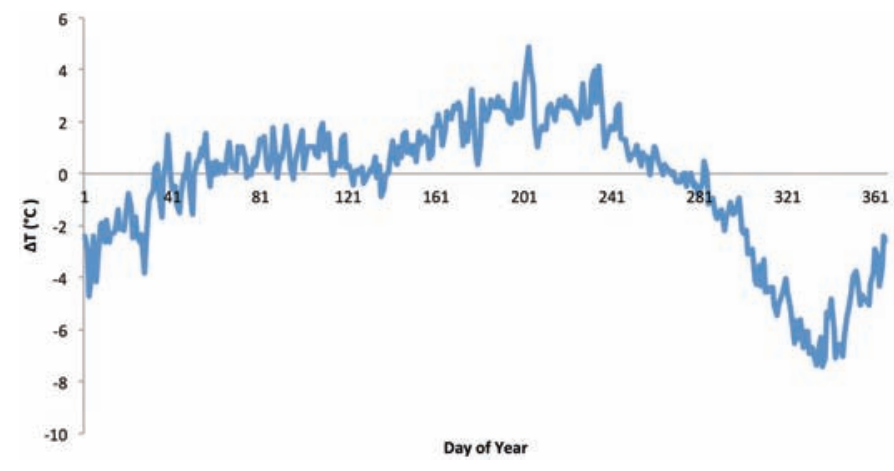

FIG. 2. Climate normal for daily $\Delta \mathrm{T}$ calculated over the period 1944-2011.

climate normal (Fig. 2) informed the definition of two temperature indices.

This high-resolution visualization of $\Delta \mathrm{T}$ made it possible to identify the period of greatest temperature asymmetry. From this visualization, the time of year when the maximum $|\Delta \mathrm{T}|$ is most likely to occur appears to lie in the range of DOY 320-350 (16 November to 16 December for normal years, 15 November to 15 December for leap years). Hence, a 31-day average of $\Delta \mathrm{T}$ covering this period was identified as $\Delta \mathrm{T}_{\mathrm{MAX}}$ and calculated for all available years.

$$
\Delta \mathrm{T}_{\mathrm{MAX}}=\Delta \mathrm{T}_{(320-350)}
$$

By averaging $\Delta \mathrm{T}$ over this specific period, we hoped to both capture the time of year when $|\Delta \mathrm{T}|$ is at its highest and eliminate some of the noise in the data. Simple linear regression was used to test the relationship between $\Delta \mathrm{T}_{\mathrm{MAX}}$ and the IFS. Multiple alternative periods were also tested for correlation to ensure that the selected $320-350$ period $\Delta \mathrm{T}_{\mathrm{MAX}}$ was indeed the $\Delta \mathrm{T}$ index most representative of the IFS. This conclusion was reaffirmed by a comparison of correlation coefficients.

\section{Benchmark}

It was necessary to establish a means of comparison for evaluating the performance of $\Delta \mathrm{T}_{\mathrm{MAX}}$ in predicting IFS. Some studies have made use of the interrelationships of ice and temperature to draw conclusions about one variable when the other is unavailable (Williams, 1971; Livingstone, 1997; Palecki and Barry, 1986). Evidently, colder temperatures in general beget a stronger, longer ice season (and a correspondingly shorter IFS). In the case of Hudson Bay, focusing on temperature during certain periods of the cryogenic cycle may produce an improved, though still coarse temperature proxy that can at least serve as a benchmark of comparison for $\Delta \mathrm{T}_{\mathrm{MAX}}$.

For simplicity and consistency, the same temperature records for Churchill and Inukjuak used to calculate $\Delta \mathrm{T}$ were used to calculate a new index of absolute temperature that is representative of the whole Bay. The two temperature records were combined into a single average temperature record for Hudson Bay. 


$$
\mathrm{T}_{\mathrm{HB}}=\frac{\left[\mathrm{T}_{\mathrm{CHURCH}}+\mathrm{T}_{\text {INUK }}\right]}{2}
$$

The period over which this spatially averaged temperature was temporally averaged was optimized to capture a period when temperature is likely to be exerting an influence on the IFS (Hochheim and Barber, 2010, 2014; Galbraith and Larouche, 2011). We selected the 61 days spanning DOY 260-320 (17 September to 16 November for regular years; 16 September to 15 November for leap years). This period $\left(T_{F}\right)$ was chosen because it encompasses the vast majority of the freeze-up process, during which air temperatures play a role in either promoting or delaying ice formation, thereby lengthening or shortening the IFS. As with $\Delta \mathrm{T}_{\mathrm{MAX}}$, the period for $\mathrm{T}_{\mathrm{F}}$ was optimized by comparing correlation coefficients with alternative periods during the freeze-up season.

$$
\mathrm{T}_{\mathrm{F}}=\mathrm{T}_{\mathrm{HB}(260-320)}
$$

Since the $\mathrm{T}_{\mathrm{F}}$ and $\Delta \mathrm{T}_{\mathrm{MAX}}$ variables differ in terms of both the temporal period over which they are measured and the underlying mechanism relating them to the IFS, it is assumed that each contributes some unique information. Thus, a multi-proxy value using both variables could in theory produce better results than either approach alone. Regression equations were therefore obtained for three proposed proxies: $\Delta \mathrm{T}_{\mathrm{MAX}}, \mathrm{T}_{\mathrm{F}}$, and $\Delta \mathrm{T}_{\mathrm{MAX}}+\mathrm{T}_{\mathrm{F}}$ (multiple regression with two independent variables for the latter). These equations were assessed as proxies on the basis of their ability to recreate the historical IFS record from 1972 to 2011. Average absolute error between actual and predicted IFS was the basis for evaluating proxy performance and selecting the best method to hindcast the IFS.

\section{Hindcast and Trend Analysis}

The regression equation associated with the best proxy method was used to generate IFS values for all years prior to 1972 with available temperature data for both Churchill and Inukjuak. The resulting hindcast time series was appended to the actual IFS time series for comparison. To determine whether there are any trends in the new time series, the Mann-Kendall statistical test was employed to produce Kendall's tau coefficients $(\tau)$ for various portions of the original time series. This non-parametric test provides a measure of rank correlation, or the probability that two variables are ranked in the same order (Kendall, 1938). The test yields a $\tau$ value between -1 and 1 , with the sign and magnitude of $\tau$ indicating the direction and probability of a correlation between two variables and a value of 0 indicating no correlation. If the independent variable is time, then that correlation corresponds to a temporal trend in the dependent variable. The test was run using the XLSTAT add-on for Microsoft Excel 2011. The hypotheses for these tests were as follows:
TABLE 1. Ice-free season (days), $\mathrm{T}_{\mathrm{F}}$ and $\mathrm{T}_{\mathrm{MAX}}\left({ }^{\circ} \mathrm{C}\right)$ for $1972-2011$.

\begin{tabular}{llrr}
\hline \hline Year & IFS & $\mathrm{T}_{\mathrm{F}}$ & $\Delta \mathrm{T}_{\mathrm{MAX}}$ \\
\hline 1972 & 111 & -5.0 & -4.1 \\
1974 & 124 & -3.0 & -1.7 \\
1975 & 143 & -0.2 & -13.4 \\
1976 & 137 & -1.9 & -5.5 \\
1977 & 149 & 1.5 & -6.9 \\
1978 & 122 & -3.1 & -1.9 \\
1979 & 143 & -3.1 & -2.3 \\
1980 & 146 & -2.6 & -7.3 \\
1981 & 153 & -0.1 & -2.4 \\
1982 & 133 & -1.6 & -10.5 \\
1983 & 137 & 0.1 & -0.2 \\
1984 & 132 & -1.8 & -5.1 \\
1985 & 131 & -1.0 & -8.6 \\
1986 & 130 & -4.2 & 0.0 \\
1987 & 128 & -1.3 & -2.8 \\
1988 & 147 & -0.2 & -9.7 \\
1989 & 141 & -2.3 & -10.3 \\
1990 & 144 & -2.6 & -12.7 \\
1991 & 141 & -2.6 & -1.9 \\
1992 & 120 & -3.2 & -6.6 \\
1993 & 135 & -2.9 & -5.3 \\
1995 & 147 & -2.1 & -9.0 \\
1996 & 151 & -0.6 & -8.4 \\
2000 & 144 & -0.2 & -9.2 \\
2001 & 164 & 0.9 & -9.6 \\
2003 & 158 & -1.0 & -8.4 \\
2004 & 134 & -0.4 & -7.6 \\
2005 & 160 & 0.9 & -8.7 \\
2006 & 170 & 0.1 & -6.2 \\
2007 & 162 & -0.4 & -5 \\
2009 & 159 & 1.9 & \\
2010 & 181 & & \\
2011 & 165 & & \\
\hline \hline & & & \\
\hline
\end{tabular}

$\mathrm{H}_{0}=$ There is no trend in the time series.

$\mathrm{H}_{\mathrm{A}}=$ There is a trend in the time series.

In order to contextualize any trends in the IFS, $\tau$ values were obtained for various periods of the extended time series. First, the hindcast time series was considered on its own as a baseline period for the IFS and compared to the actual time series in terms of $\tau$. In order to identify the period when it is most probable that a trend is occurring, additional analyses were done using arbitrarily defined division points in the dataset at five-year intervals from 1980 to 1990 . This procedure serves to highlight any contrasts in trend probability between earlier and later portions of the record.

\section{RESULTS}

The values of IFS, $\Delta \mathrm{T}_{\mathrm{MAX}}$, and $\mathrm{T}_{\mathrm{F}}$ for the period 1972-2011 are presented in Table 1. Linear regression between IFS and $\Delta \mathrm{T}_{\mathrm{MAX}}$ yields a statistically significant negative correlation $(\mathrm{R}=-0.50, p=0.003)$. Note that, by our definition of $\Delta \mathrm{T}$, a negative correlation means that a longer IFS is more likely to be associated with a higher $\left|\Delta \mathrm{T}_{\mathrm{MAX}}\right|$. The following equation describes that linear relationship: 
TABLE 2. Actual IFS compared in terms of absolute error (days) to IFS predicted by $\Delta \mathrm{T}_{\mathrm{MAX}}, \mathrm{T}_{\mathrm{F}}$, and $\Delta \mathrm{T}_{\mathrm{MAX}}+\mathrm{T}_{\mathrm{F}}$ linear relationships

\begin{tabular}{|c|c|c|c|c|c|c|c|}
\hline \multirow[b]{2}{*}{ Year } & \multirow[b]{2}{*}{ IFS (Actual) } & \multicolumn{2}{|c|}{$\Delta \mathrm{T}_{\mathrm{MAX}}$} & \multicolumn{2}{|c|}{$\mathrm{T}_{\mathrm{F}}$} & \multicolumn{2}{|c|}{$\Delta \mathrm{T}_{\mathrm{MAX}}+\mathrm{T}_{\mathrm{F}}$} \\
\hline & & IFS & $\mid$ Error $\mid$ & IFS & |Error| & IFS & |Error| \\
\hline 1972 & 111 & 138 & 27 & 118 & 7 & 118 & 7 \\
\hline 1974 & 124 & 132 & 8 & 131 & 7 & 128 & 4 \\
\hline 1975 & 143 & 159 & 16 & 151 & 8 & 156 & 13 \\
\hline 1976 & 137 & 141 & 4 & 139 & 2 & 138 & 1 \\
\hline 1977 & 149 & 144 & 5 & 163 & 14 & 161 & 12 \\
\hline 1978 & 122 & 133 & 11 & 131 & 9 & 128 & 6 \\
\hline 1979 & 143 & 134 & 9 & 131 & 12 & 128 & 15 \\
\hline 1980 & 146 & 145 & 1 & 134 & 12 & 136 & 10 \\
\hline 1981 & 153 & 134 & 19 & 152 & 1 & 146 & 7 \\
\hline 1982 & 133 & 152 & 19 & 141 & 8 & 145 & 12 \\
\hline 1983 & 137 & 129 & 8 & 153 & 16 & 145 & 8 \\
\hline 1984 & 132 & 140 & 8 & 140 & 8 & 138 & 6 \\
\hline 1985 & 131 & 148 & 17 & 145 & 14 & 147 & 16 \\
\hline 1986 & 130 & 129 & 1 & 123 & 7 & 119 & 11 \\
\hline 1987 & 128 & 135 & 7 & 143 & 15 & 140 & 12 \\
\hline 1988 & 147 & 150 & 3 & 151 & 4 & 152 & 5 \\
\hline 1989 & 141 & 146 & 5 & 136 & 5 & 138 & 3 \\
\hline 1990 & 144 & 152 & 8 & 134 & 10 & 139 & 5 \\
\hline 1991 & 141 & 157 & 16 & 134 & 7 & 141 & 0 \\
\hline 1992 & 120 & 133 & 13 & 130 & 10 & 127 & 7 \\
\hline 1993 & 135 & 143 & 8 & 132 & 3 & 134 & 1 \\
\hline 1995 & 147 & 141 & 6 & 138 & 9 & 137 & 10 \\
\hline 1996 & 151 & 149 & 2 & 148 & 3 & 150 & 2 \\
\hline 2000 & 144 & 147 & 3 & 151 & 7 & 152 & 8 \\
\hline 2001 & 164 & 150 & 14 & 158 & 6 & 159 & 5 \\
\hline 2003 & 158 & 150 & 8 & 145 & 13 & 148 & 10 \\
\hline 2004 & 134 & 147 & 13 & 149 & 15 & 150 & 16 \\
\hline 2005 & 160 & 146 & 14 & 158 & 2 & 157 & 3 \\
\hline 2006 & 170 & 150 & 20 & 153 & 17 & 155 & 15 \\
\hline 2007 & 162 & 147 & 15 & 150 & 13 & 150 & 12 \\
\hline 2009 & 159 & 143 & 16 & 149 & 10 & 148 & 11 \\
\hline 2010 & 181 & 153 & 28 & 166 & 15 & 167 & 14 \\
\hline 2011 & 165 & 147 & 18 & 165 & 0 & 164 & 1 \\
\hline Average & & & 11.2 & & 8.8 & & 8.1 \\
\hline SD & & & 7.0 & & 4.7 & & 4.7 \\
\hline
\end{tabular}

$$
\mathrm{IFS}=128.6-2.24 \cdot \Delta \mathrm{T}_{\mathrm{MAX}}
$$

Linear regression between IFS and $T_{F}$ reveals a statistically significant negative relationship $\left(\mathrm{R}^{2}=0.59, p<\right.$ $0.0001)$ described by the following linear equation:

$$
\text { IFS }=152.2+6.92 \cdot \mathrm{T}_{\mathrm{F}}
$$

The multiple regression with both $\Delta \mathrm{T}_{\mathrm{MAX}}$ and $\mathrm{T}_{\mathrm{F}}$ as independent variables yields a statistically significant relationship $\left(\mathrm{R}^{2}=0.63, p<0.0001\right)$ described by the following equation:

$$
\text { IFS }=144.6-0.96 \cdot \Delta \mathrm{T}_{\mathrm{MAX}}+6.06 \cdot \mathrm{T}_{\mathrm{F}}
$$

When all $\Delta \mathrm{T}_{\mathrm{MAX}}$ and $\mathrm{T}_{\mathrm{F}}$ values on record from the period 1972-2011 are used as inputs into these three equations, predicted values of the IFS are produced for each of the proposed proxies (Table 2). The absolute difference between predicted IFS and actual IFS is shown in the |Error| column. The average absolute error provides an effective means of comparing proxy performance among the three methods. By this measure, $\Delta \mathrm{T}_{\mathrm{MAX}}$ alone is definitely the least accurate in replicating the historical IFS record. The $T_{F}$ method outperforms $\Delta \mathrm{T}_{\mathrm{MAX}}$ significantly; however, it is the multiproxy method that has the lowest associated error (8.1 days).
The extended time series derived using the multi-proxy method is shown in Figure 3. Gaps in the data indicate years for which ice data were incomplete. The Mann-Kendall test conducted on the entire time series (1944-2011) showed a weak positive association between time and IFS that is statistically significant at the $95 \%$ confidence interval $(\tau=0.21, p=0.017)$. Since it is assumed that this positive trend is being driven by a recent increase in the IFS, the test was run for four different pairs of baseline/trend time series, defined by a division year (Table 3). The first entry (1972) uses the entire hindcast record as a baseline and the entire actual record as a trend. The other three entries were arbitrarily selected at intervals of five years starting in 1980 in an effort to isolate the period in which a trend is most likely. As another example, the second entry in Table 3 (1980) has a baseline $\tau$ and $p$-value that correspond to the period 1944-80. That same entry has a trend $\tau$ and $p$-value that correspond to $1980-2011$, and so on. Of the four pairs of baseline and trend time series presented in Table 3, those with the division year of 1985 have the greatest contrast. For the period $1944-85$, there is no statistically significant trend occurring, while the $\tau$ value of 0.607 for the period 1986-2011 strongly suggests a statistically significant positive trend in IFS with time $(p<0.0001)$. 
TABLE 3. Comparison between baseline and trend in terms of $\tau$ and statistical significance for arbitrary division points in the IFS time series.

\begin{tabular}{lcccc}
\hline \hline Division & Baseline $\tau$ & Trend $\tau$ & Baseline $p$ & Trend $p$ \\
\hline 1972 & 0.177 & 0.490 & 0.198 & $<0.0001$ \\
1980 & -0.024 & 0.484 & 0.848 & 0.0004 \\
1985 & -0.033 & 0.607 & 0.770 & $<0.0001$ \\
1990 & -0.088 & 0.578 & 0.399 & 0.001 \\
\hline \hline
\end{tabular}

\section{DISCUSSION AND CONCLUSIONS}

The statistically significant negative correlation between IFS and $\Delta \mathrm{T}_{\mathrm{MAX}}(\mathrm{R}=-0.50, p=0.003)$ suggests that the length of time the Bay is ice-free has some effect on the temperature asymmetry following the end of the IFS. More specifically, a shorter IFS tends to be associated with smaller $\left|\Delta \mathrm{T}_{\mathrm{MAX}}\right|$ (closer to zero), while a longer IFS tends to be associated with greater $\left|\Delta \mathrm{T}_{\mathrm{MAX}}\right|$ values. However, this relationship exhibits a great degree of variability, so that years with an average or below-average IFS can also have a significantly large $\left|\Delta T_{\text {MAX }}\right|$ signal. Indeed, the top two years in terms of magnitude of $\Delta \mathrm{T}_{\mathrm{MAX}}(-13.4,-12.7)$ were not coincident with a uniquely long IFS, but rather with average years (IFS $=143$ and 141, respectively). The converse of this problem occurs as well, as there are years with a lengthy IFS but very little temperature asymmetry. For example, the $\Delta \mathrm{T}_{\mathrm{MAX}}$ value of -2.4 occurs during a year with an IFS $=153$. Such examples are less common, however, and in general it seems as though $\Delta \mathrm{T}_{\mathrm{MAX}}$ values closer to 0 are more reliably associated with shorter IFS, while the larger $\left|\Delta \mathrm{T}_{\mathrm{MAX}}\right|$ values are not as consistently associated with the longer IFS. Consider that of the top 10 years in terms of high $\left|\Delta \mathrm{T}_{\mathrm{MAX}}\right|$, only five are also top 10 years in terms of IFS. However, of the bottom 10 years in terms of $\left|\Delta \mathrm{T}_{\mathrm{MAX}}\right|$ (i.e., closest to zero), seven are also in the bottom 10 in terms of IFS. This suggests that large temperature differences between coasts may arise under a slightly wider range of IFS, whereas smaller temperature differences are more often constrained to years when IFS was below average.

As a result of this inconsistent relationship between IFS and $\Delta \mathrm{T}_{\mathrm{MAX}}$, applying its regression equation to the temperature record for 1972-2011 yields a relatively poor reconstruction of actual IFS. Absolute error values range from 1 to 28 days and average 11.2 days. Temperature during freeze-up was also shown to have a statistically significant negative correlation with IFS $\left(\mathrm{R}^{2}=0.59, p=<0.0001\right)$. This result is to be expected, since colder temperatures during the freeze-up period would tend to expedite sea ice formation, leading to a shorter IFS (and warmer temperatures would tend to delay freeze-up, producing the opposite effect). $T_{F}$ clearly explains more of the variability in IFS than $\Delta \mathrm{T}_{\mathrm{MAX}}$ does. Using its regression equation to reconstruct IFS yields an average absolute error of 8.8 days, a 2.4-day improvement over $\Delta \mathrm{T}_{\mathrm{MAX}}$.

The relationships that $\Delta \mathrm{T}_{\mathrm{MAX}}$ and $\mathrm{T}_{\mathrm{F}}$ each exhibit with IFS suggest that both variables contain some unique

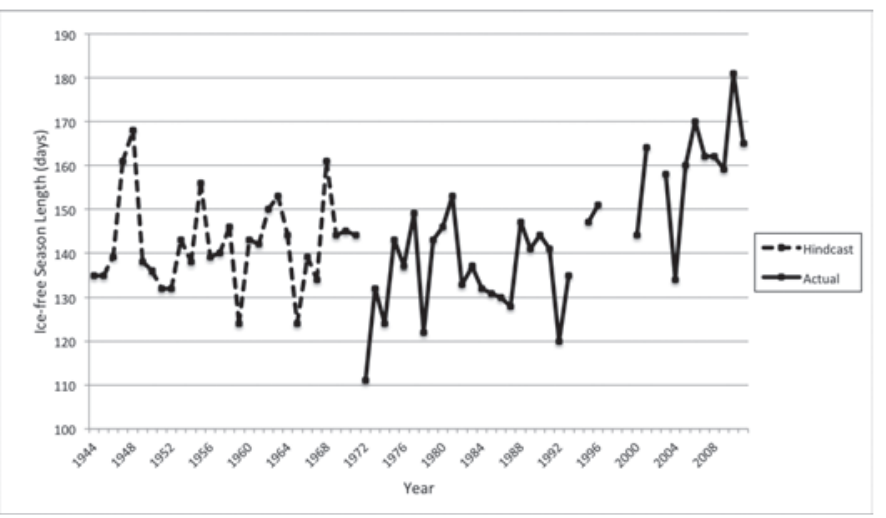

FIG. 3. Time series of IFS from 1944 to 2011 constructed using actual observations and data derived by proxy from equation 7 .

information regarding ice-free season length. Although both variables are indices of mean air temperature, they are different in terms of both the temporal period over which they are calculated and the underlying mechanisms that relate them to IFS. In the case of $\Delta \mathrm{T}_{\mathrm{MAX}}$, it is the sea ice (or lack thereof) acting upon advecting air that leads to the temperature difference signal. In the case of $T_{F}$, however, it is $\mathrm{T}_{\mathrm{F}}$ that is acting upon the sea ice (or open water), hence playing a role in determining the IFS. Furthermore, despite being the most highly correlated to IFS, $\mathrm{T}_{\mathrm{F}}$ by definition contains only information regarding freeze-up conditions. By contrast, $\Delta \mathrm{T}_{\mathrm{MAX}}$ is theoretically determined by the cumulative effects of open water, and hence should inherently contain some information regarding breakup conditions, which are equally determinant of the IFS. Therefore, the information contained in $\mathrm{T}_{\mathrm{F}}$ and $\Delta \mathrm{T}_{\mathrm{MAX}}$ with respect to IFS should not be redundant, and a multiple regression employing both temperature variables is expected to yield a more significant relationship than either variable alone. Indeed, the inclusion of the temperature difference metric allows for a more accurate hindcast, as evidenced by the average absolute error result of 8.1 days. This result represents a $9 \%$ improvement over the $\mathrm{T}_{\mathrm{F}}$ method in predicting historical values and establishes the multi-proxy method as the best option for hindcasting IFS.

Making use of this novel proxy method to hindcast icefree season produces 28 new data points that offer valuable insight into sea ice conditions prior to 1972. More importantly, it establishes a baseline that makes the recent increase more significant by contrast. The high interannual variability of IFS throughout this record is a quality that should be expected, given the inherent variability of sea ice and driving climate factors. Even considering this variability, however, the tendency towards higher IFS in the most recent decades had no precedents in the earlier period (1944 to 1995), when IFS values generally ranged from 120 to 160 days (with a few exceptions in 1947, 1948, 1968, and 1972). After 1995, short IFSs appear to be less frequent; only one year (2004) had an IFS below 140 days. Conversely, long IFSs appear to become more frequent, with seven years having an IFS longer than 160 days. 
The results of trend analysis by the Mann-Kendall test confirm what is visually apparent: an upward trend in the later decades not present in the earlier decades. The $\tau$ value of 0.208 for the entire time series (1944-2011) hints at a trend, but this value is likely being diluted by the lengthy period when there is no trend. When considering only the later decades of the time series, the trend becomes more apparent and statistically significant. Of the four arbitrarily selected "trend" time periods, all produce $\tau$ values indicative of positive trends that are statistically significant at the $99 \%$ confidence level. By contrast, none of the accompanying baseline periods exhibit any significant trends. The period with the greatest evidence for a positive trend in IFS is that of $1985-2011(\tau=0.61, p<0.0001)$. Therefore, from this lengthened time series it can be concluded that the recent increase in IFS had no precedent during the period 1944-85, and hence is unlikely to be a result of natural climate variability. However, even the 68 -year record cannot conclusively eliminate all sources of climatic variability in this manner, as there exist low-frequency climate oscillations on larger time scales that this time series cannot capture (Mahasenan et al., 1997). Thus, the extended time series provides support that the recent increasing trend in ice-free season on Hudson Bay is not attributable to lowfrequency climate oscillations of a periodicity below 68 years. We do recognize that climate oscillations of shorter duration, ENSO (El Nino/Southern Oscillation) and NAO (North Atlantic Oscillation) have been detected in the Hudson Bay sea ice, temperature, and river discharge data (Wang et al., 1994; Mysak et al., 1996; Déry and Wood, 2004; Gough et al., 2004a; Déry et al., 2005). Of particular interest to this work is the Atlantic Multi-decadal Oscillation (AMO), which has a cycle of approximately 30 years. Tivy et al. (2011) hypothesized that recent changes in sea ice and its concurrent temperatures in Hudson Bay may be the result of a change of phase in the AMO that occurred in the mid to late 1990s (the AMO switched from a negative phase to a positive phase). Consistent with this hypothesis, a shift in sea ice distribution (and concurrent temperatures) should have occurred in the early 1960s, when the phase changed from positive to negative. The results of this study (Fig. 3) do not support this hypothesis, as no trend is detected during the period from 1944 to 1985. Furthermore, the statistical analysis of the time series suggests that the recent change began in the mid-1980s rather than the 1990s.

Further research into this and other proxies may yield a more accurate method for hindcasting sea ice conditions, as several factors are unaccounted for in this simplified approach. Preliminary analyses showed an inverse correlation between $\left|\Delta \mathrm{T}_{\mathrm{MAX}}\right|$ and the frequency of easterly and northeasterly winds in Inukjuak. Given that the temperature asymmetry is reliant upon air masses having advected over the Bay prior to influencing the east coast air temperature, such a relationship is not surprising. Accounting for wind direction in the proposed proxy might mitigate some of the error associated with it, but is precluded by an absence of observations for Inukjuak prior to 1981. Experimentation with the $T_{F}$ variable that makes use of other climate stations or a focus on different periods of the cryogenic cycle might also yield better results. Any proxy method must acknowledge the spatial limitations imposed by the complexity of sea ice-atmosphere interaction and the heterogeneity of sea ice on the Bay. Complicating factors no doubt place certain limitations on the spatiotemporal resolution and simplicity of sea ice proxies based solely on meteorological variables. Furthermore, in the context of Hudson Bay, a limit on temporal accuracy of one week is imposed on any proxy reliant on CIS ice concentration data. Regardless of the potential for improvement, the proposed proxy method fulfills its purpose by establishing a baseline for comparison of the recent trend in ice-free season on the Bay. Hindcast data help eliminate low-frequency climate oscillations with periodicity of less than 68 years as a source of this trend, lending further evidence to the growing consensus that a decline in sea ice is the result of anthropogenic climate forcing. While the east-west temperature asymmetry has been shown to have little predictive value on its own, its inclusion leads to a novel multi-proxy with improved accuracy and utility for characterizing Hudson Bay sea ice.

\section{ACKNOWLEDGEMENTS}

We gratefully acknowledge Dr. Alexandre Gagnon and Slawomir Kowal who supplied the sea ice data. We thank Dr. Ken Butler for statistical advice, as well as Shannon Allen for assisting with temperature data.

\section{REFERENCES}

Déry, S.J., and Wood, E.F. 2004. Teleconnection between the Arctic Oscillation and Hudson Bay river discharge. Geophysical Research Letters 31: L18205. http://dx.doi.org/10.1029/2004GL020729

Déry, S.J., Stieglitz, M., McKenna, E.C., and Wood, E.F. 2005. Characteristics and trends of river discharge into Hudson, James, and Ungava Bays, 1964-2000. Journal of Climate 18(4):2540-2557.

http://dx.doi.org/10.1175/JCLI3440.1

Etkin, D.A. 1991. Break-up in Hudson Bay: Its sensitivity to air temperatures and implications for climate warming. Climatological Bulletin 25(1):21-34.

Gagnon, A.S., and Gough, W.A. 2005. Trends in the dates of ice freeze-up and breakup over Hudson Bay, Canada. Arctic 58(4):370-382.

http://dx.doi.org/10.14430/arctic451

Galbraith, P.S., and Larouche, P. 2011. Sea-surface temperature in Hudson Bay and Hudson Strait in relation to air temperature and ice cover breakup, 1985-2009. Journal of Marine Systems 87(1):66-78.

http://dx.doi.org/10.1016/j.jmarsys.2011.03.002 
Gerbush, M.R., Kristovich, D.A.R., and Laird, N.F. 2008. Mesoscale boundary layer and heat flux variations over pack ice-covered Lake Erie. Journal of Applied Meteorology and Climatology 47(2):668-682. http://dx.doi.org/10.1175/2007JAMC1479.1

Gough, W.A., and Allakhverdova, T. 1999. Limitations of using a coarse resolution model to assess the impact of climate change on sea ice in Hudson Bay. The Canadian Geographer 43(4):415-422. http://dx.doi.org/10.1111/j.1541-0064.1999.tb01398.x

Gough, W.A., and Houser, C. 2005. Climate memory and longrange forecasting of sea ice conditions in Hudson Strait. Polar Geography 29(1):17-26.

http://dx.doi.org/10.1080/789610163

Gough, W.A., Cornwell, A.R., and Tsuji, L.J.S. 2004a. Trends in seasonal sea ice duration in southwestern Hudson Bay. Arctic 57(3):299-305.

http://dx.doi.org/10.14430/arctic507

Gough, W.A., Gagnon, A.S., and Lau, H.P. 2004b. Interannual variability of Hudson Bay ice thickness. Polar Geography 28(3):222-238.

http://dx.doi.org/10.1080/789610188

Hochheim, K.P., and Barber, D.G. 2010. Atmospheric forcing of sea ice in Hudson Bay during the fall period, 1980-2005. Journal of Geophysical Research 115: C05009. http://dx.doi.org/10.1029/2009JC005334

- 2014. An update on the ice climatology of the Hudson Bay system. Arctic, Antarctic, and Alpine Research 46(1):66-83. http://dx.doi.org/10.1657/1938-4246-46.1.66

Hochheim, K.P., Lukovich, J.V., and Barber, D.G. 2011. Atmospheric forcing of sea ice in Hudson Bay during the spring period, 1980-2005. Journal of Marine Systems 88(3):476-487.

http://dx.doi.org/10.1016/j.jmarsys.2011.05.003

Isaksson, E., Kohler, J., Pohjola, V., Moore, J., Igarashi, M., Karlöf, L., Martma, T., et al. 2005. Two ice-core $\delta^{18} \mathrm{O}$ records from Svalbard illustrating climate and sea-ice variability over the last 400 years. The Holocene 15(4):501-509.

http://dx.doi.org/10.1191/0959683605hl820rp

Joly, S., Senneville, S., Caya, D., and Saucier, F.J. 2011. Sensitivity of Hudson Bay sea ice and ocean climate to atmospheric temperature forcing. Climate Dynamics 36(9-10):1835-1849. http://dx.doi.org/10.1007/s00382-009-0731-4

Kendall, M.G. 1938. A new measure of rank correlation. Biometrika 30(1-2):81-93.

http://dx.doi.org/10.1093/biomet/30.1-2.81

Livingstone, D.M. 1997. Break-up dates of alpine lakes as proxy data for local and regional mean surface air temperatures. Climatic Change 37(2):407-439.

http://dx.doi.org/10.1023/A:1005371925924

Macias Fauria, M., Grinsted, A., Helama, S., Moore, J., Timonen, M., Martma, T., Isaksson, E., and Eronen, M. 2010. Unprecedented low twentieth century winter sea ice extent in the Western Nordic Seas since A.D. 1200. Climate Dynamics 34(6):781-795.

http://dx.doi.org/10.1007/s00382-009-0610-z
Mahasenan, N., Watts, R.G., and Dowlatabadi, H. 1997. Lowfrequency oscillations in temperature-proxy records and implications for recent climate change. Geophysical Research Letters 24(5):563-566.

http://dx.doi.org/10.1029/97GL00319

Martini, I.P. 1986. Coastal features of Canadian inland seas. In: Martini, I.P., ed. Canadian inland seas. Elsevier Oceanography Series 44, Chapter 7. Amsterdam: Elsevier. 117-142. http://dx.doi.org/10.1016/S0422-9894(08)70900-0

McPhee, M. 2008. Air-ice-ocean interaction: Turbulent ocean boundary layer exchange processes. New York: Springer.

Mysak, L.A., Ingram, R.G., Wang, J., and van der Baaren, A. 1996. The anomalous sea-ice extent in Hudson Bay, Baffin Bay and the Labrador Sea during three simultaneous NAO and ENSO episodes. Atmosphere-Ocean 34(2):313-343.

http://dx.doi.org/10.1080/07055900.1996.9649567

Niziol, T.A. 1987. Operational forecasting of lake effect snowfall in Western and Central New York. Weather and Forecasting 2(4):310-321.

http://dx.doi.org/10.1175/1520-0434(1987)002<0310:OFOLES $>2.0 . \mathrm{CO} ; 2$

Palecki, M.A., and Barry, R.G. 1986. Freeze-up and break-up of lakes as an index of temperature changes during the transition seasons: A case study for Finland. Journal of Climate and Applied Meteorology 25(7):893-902.

http://dx.doi.org/10.1175/1520-0450(1986)025<0893:FUABUO $>2.0 . \mathrm{CO} ; 2$

Polyak, L., Alley, R.B., Andrews, J.T., Brigham-Grette, J., Cronin, T.M., Darby, D.A., Dyke, A.S., et al. 2010. History of sea ice in the Arctic. Quaternary Science Reviews 29:1757-1778. http://dx.doi.org/10.1016/j.quascirev.2010.02.010

Saucier, F.J., and Dionne, J. 1998. A 3-D coupled ice-ocean model applied to Hudson Bay, Canada: The seasonal cycle and timedependent climate response to atmospheric forcing and runoff. Journal of Geophysical Research 103(C12):27689-27705. http://dx.doi.org/10.1029/98JC02066

Stirling, I., Lunn, N.J., and Iacozza, J. 1999. Long-term trends in the population ecology of polar bears in western Hudson Bay in relation to climatic change. Arctic 52(3):294-306. http://dx.doi.org/10.14430/arctic935

Tivy, A., Alt, B., Howell, S., Wilson, K., and Yackel, J. 2007. Long-range prediction of the shipping season in Hudson Bay: A statistical approach. Weather and Forecasting 22(5):1063-1075. http://dx.doi.org/10.1175/WAF1038.1

Tivy, A., Howell, S.E.L., Alt, B., Yackel, J.J., and Carrieres, T. 2011. Origins and levels of seasonal forecast skill for sea ice in Hudson Bay using canonical correlation analysis. Journal of Climate 24(5):1378-1395. http://dx.doi.org/10.1175/2010JCLI3527.1

Wang, J., Mysak, L.A., and Ingram, R.G. 1994. Interannual variability of sea-ice cover in Hudson Bay, Baffin Bay and the Labrador Sea. Atmosphere-Ocean 32(2):421 - 447. http://dx.doi.org/10.1080/07055900.1994.9649505

Williams, G.P. 1971. Predicting the date of lake ice breakup. Water Resources Research 7(2):323-333. http://dx.doi.org/10.1029/WR007i002p00323 